\title{
Structural Ambidexterity: Exploring Alternative Pro- Ambidexterity Conducive Structural Designs for Recourse-Constrained Organizations
}

\author{
Muhammad Yousuf Khan Marri \\ School of Business Management, \\ Universiti Utara Malaysia \\ Soo Hooi Sin \\ School of Business Management, \\ Universiti Utara Malaysia \\ Hassan Ali \\ Kolej MDIS Malaysia, \\ Johor Bahru, Malaysia
}

\begin{abstract}
Organizational ambidexterity is of paramount importance for the long term success of business organizations operating in an uncertain and dynamic environment. Although the role of a structure by means of structural differentiation (structural ambidexterity) advocated and supported for attaining organizational ambidexterity, however, it has also received criticism for being counterproductive for recourse-constrained organizations. Despite the fact, less focus has been devoted to finding alternative organizational structural design approaches for predicting organizational ambidexterity in resource-deficient organizations. To heed such persisting knowledge gap, this study highlighted four possible alternative organizational structural designs that may be useful for resolving the exploration and exploitation tension and attaining organizational ambidexterity in resource-constrained originations. Such an effort will serve as a reference for future conceptual and empirical research in organizational design and ambidexterity literature.
\end{abstract}

Keywords: Structural ambidexterity, mechanic structure, organic structure, exploration \& exploitation, organizational ambidexterity, resource-constrained organizations.

\section{INTRODUCTION}

The inexorable advance of globalization has forced organizations to consolidate existing businesses while simultaneously pursuit new opportunities for long term success. Earmarked for the purpose, organizations need to resolve and manage the ingrained tension between exploration and exploitation activities simultaneously. Where exploration is the experimentation of new alternatives and exploitation is refinement and extension of existing competencies, technologies, and paradigms (March, 1991). Simultaneous pursuit of such paradoxical activates (exploration and exploitation) is termed organizational ambidexterity, which is predominantly suggested a solution for organizational survival and success (Agostini, Nosella, \& Filippini, 2016; Junni, Sarala, Taras, \& Tarba, 2013; 0'Reilly \& Tushman, 2013; Pertusa-Ortega, \& Molina-Azorín, 2018).

How organizational ambidexterity (OA) is achieved is an ongoing dominant debate in the literature, which largely suggests two pathways, i.e. structural differentiation (Tushman \& O'Reilly, 1996) and organizational context (Gibson \& Birkinshaw, 2004), that enable an organization to balance paradoxical demands of exploration and exploitation and achieve 
ambidexterity. Although structural approach to ambidexterity has received support in primary studies (e.g. Agostini et al., 2016; Pertusa-Ortega, \& Molina-Azorín, 2018), however concerns were raised about its feasibility for resource-constrained organizations (e.g., Burgers \& Covin, 2016; Fourné, Rosenbusch, Heyden, \& Jansen, 2019; Gatignon \& Xuereb, 1997; Gupta, Smith \& Shalley, 2006; Hill \& Birkinshaw, 2014; Lubatkin, Simsek, Ling, \& Veiga ,2006; Lyytinen, Rose \& Yoo, 2010; Martin, Keller, \& Fortwengel, 2019; Patel, Messersmith, \& Lepak, 2013).

Unfortunately, less focus has been devoted towards finding alternative organizational structural design approaches in literature that may lead to in attaining OA (Chang \& Hudges, 2012; Jansen, Tempelaar, Van den Bosch, \& Volberda, 2009; Junni, Sarala, Tarba, Liu \& Cooper, 2015; Pertusa-Ortega, \& Molina-Azorín, 2018), more specifically in resource-constrained organizations.

Therefore, this study attempts to fill this gap in the literature by exploring alternative designs other than largely proposed structural differentiation. More specifically, in contrast to structural differentiation, this review paper explores how organizational structure characterized by a combination of mechanistic and organic features or individual structure in an organizational operational level could be an alternative solution, more explicitly for resource-constrained organizations. Such an effort could be vital for academicians and practitioners interested in developing theories and strategies to achieve $\mathrm{OA}$ for organizational long term success.

This paper henceforward is organized as follows. The next section briefly presents a conceptual background of structural ambidexterity. Then, this study critically evaluates the literature on structural ambidexterity. Afterward, a possible combination of or individual structural design approaches will be discussed. Finally, the paper concludes by discussing the need for a conducive structural design approach which may lay a solid foundation for future research in resource-constrained organizations.

\section{STRUCTURAL AMBIDEXTERITY}

Resolving the challenge of efficiency and flexibility remained a focal point of scholars in organization theory and management literature. Thompson (1967), for instance, characterizes the trade-off between efficiency and flexibility as a crucial "paradox of administration". Responding to such paradox, Burns and Stalker (1961) in their study introduced mechanistic and organic structures and outlined the differences between the two types. According to them mechanistic structures-which rest on standardization, centralization, and hierarchysupport efficiency, whereas organic structures-which based on decentralization and autonomy - support flexibility. Further, they proposed that structural designs containing mechanistic features are appropriate for organizations operating in stable business environment, whereas an organic approach is adequate for constantly changing business environment, which constantly gives rise to new problems and unforeseen requirements and requires certain actions and steps to be taken which cannot be carried out through mechanistic structural arrangements.

Based on Burns and Stalker's (1961) solid impactful conceptualization of organizational design, Duncan (1976) was the first to coin the term ambidextrous and argued that an organization needs to be ambidextrous for its prosperity by addressing both flexibility and efficiency. Thereby, he maintained that organizations require both structural approaches i.e. organic structure (for innovations creation) and mechanistic structure (for implementation). However, he implied that for accommodating the conflicting alignments of innovation and 
efficiency, organizations need to shift their structural arrangements over time to align the structure with the organization's strategy aimed for innovation and flexibility. In other words, ambidexterity can be achieved in a sequential style by aligning the structures accordingly over time. Despite the fact that several authors (Ford \& Ford, 1994; Lawrence \& Lorsch, 1967; Lewis, 2000), disavowed his viewpoint by auguring that mechanistic and organic structures are hard to be reconciled within a single organization.

Responding to the reconciling issue of both structural approaches and dissenting with the sequential approach of shifting structures overtime, Tushman and O'Reilly (1996) in their seminal research set a new benchmark by arguing that in fast-changing business environment sequential ambidexterity might be fruitless, as organizations need to explore and exploit synchronously. They suggested that this could be accomplished by establishing autonomous exploration and exploitation subunits that were structurally separated. Such an approach to pursuing exploration and exploitation through creating structural differentiation is termed structural ambidexterity (Raisch \& Birkinshaw, 2008; Tushman \& O’Reilly, 1996).

Alternatively stated, structural ambidexterity advocates that paradoxical challenge of addressing both exploration and exploitation concurrently could be managed by structurally separating them in different units (Jansen et al., 2009; Lavie, Stettner \& Tushman, 2010; Lavie, Kang, \& Rosenkopf, 2011; O'Reilly \& Tushman, 2008, 2013). Such independent units could be founded on different proficiencies, incentives, practices, and values that are internally aligned and explicitly customized required to address exploration or exploitation processes (Gilbert, 2006; O’Reilly \& Tushman 2008; Tushman \& O’Reilly 1996). Such an arrangement may buffer exploration from exploitation (Tushman \& O'Reilly, 1996) and helps to overcome resource and routine rigidity (Gilbert, 2006). It allows for aim-oriented systems, clarity in an objective, processes, and incentives that are all geared towards specialization within units of the organization (Benner \& Tushman, 2003; Simsek, 2009; Tushman \& O'Reilly, 1996). Such different processes and specialization protect the activities of the exploration unit from potentially rigid cultural and procedural externalities from the standard business operations (Benner \& Tushman, 2003; Gilbert 2006).

In separate unit system, for instance, exploitation unit can focus on improving existing products and services rather than worrying about future business concerns (Jansen et al. 2009; Simsek, 2009), and exploration units, on the other hand, may focus on exploring new opportunities without much concerning about the efficiency of the existing operations. Thereby, the unit engaged in exploitation-oriented activities usually characterized by mechanistic structural design, with centralized decision making, less flexible cultures, and a focus on efficiency and control (Benner \& Tushman 2003). Whereas, the exploration-oriented unit tends to be more characterized with organic design, with more decentralized decision making, entrepreneurial cultures, with a focus on flexibility (Boumgarden, Nickerson, Zenger, 2012; Lavie et al., 2010).

Since dual structure operates independently within an organization, teams of both units lack due cooperation, the units tightly integrated at management level. Consequently, the role of senior management is crucial to deal with integration challenges of exploration and exploitation and devise strategic measures for reconciling them at the organizational level (Burgers, Jansen, Van den Bosch, Volberda, 2008, Fourné, et al., 2019; Jansen et al. 2009; Mom, Van Den Bosch, \& Volberda, 2009). In other words, the integrative mechanisms required in pursuing structural ambidexterity to large extent a leadership issue than mere separation of units (Chen \& Kannan-Narasimhan, 2015; Gassmann, Widenmayer \& Zeschky, 2012; Hansen; Wicki \& Schaltegger, 2018; Heracleous, Papachroni, Andriopoulos \& Gotsi, 2017; Jansen, 
George, Van den Bosch \& Volberda, 2008; Nemanich \& Vera, 2009; O'Reilly \& Tushman, 2011; Smith \& Tushman, 2005). So far, pertaining to dual structure or structural differentiation's effect on organizational ambidexterity yield mixed results with positive (e.g. Dutta, 2015; Junni, et al., 2013; Pertusa-Ortega, \& Molina-Azorín, 2018) to no effects (e.g. Chandrasekaran, Linderman, \& Schroeder, 2012; Hansen et al., 2018)

\section{EXISTING DISCREPANCIES IN STRUCTURAL DIFFERENTIATION APPROACH}

As explained earlier that the bottom line of structural separation that subunits can focus on their mandate and boundaries and can excel based on capabilities. For instance, the production unit can serve existing customer-base without any distraction or pressure for innovation. On the contrary, the exploration-oriented unit can concentrate solely on exploration (new customers/ market) without being worried about efficiency requirements. However, because both sequential and structural ambidextrous organization designs i.e. (sequential and structural ambidexterity) is composed of highly differentiated with weak integration mechanisms, neither design can function effectively with highly-constrained time and space. Therefore, structural and sequential approaches towards ambidexterity face inertia and delays when shifting from exploration to exploitation, and vice versa (Asif, 2017; Lyytinen et al., 2010). Further, it has been argued that structural separation or differentiation approach can lead to the disjunction of different units, a failure to manoeuver efforts carried out by the units, and inability to take advantage of potential synergies of different units (Agostini et al., 2016; Asif, 2017). Further, structural differentiation can cause self-centered behaviors, where managers of different units may perceive direct competition with other units run for scarce resources (Asif, 2017; Chen \& Kannan-Narasimhan, 2015; Gassmann et al., 2012). To mitigate such challenges, it has been suggested that behavioral integration in teams could be productive to reconcile conflicting expectations of different units that can translate antagonistic demands into a workable strategy (Fourné et al., 2019; Jansen et al., 2009). Further, the formation of common goals, set of values, and structural linking mechanisms can help in reducing the isolation among units in the structural differentiation approach (Raisch \& Birkinshaw, 2008; Simsek, 2009).

Having said that structural separation is considered a key pathway to organizational ambidexterity, such approach can be less productive or even counterproductive for resourceconstrained organizations (e.g., Burgers \& Covin, 2016; Fourné et al., 2019; Gatignon \& Xuereb, 1997; Gupta et al., 2006; Hill \& Birkinshaw, 2014; Lubatkin et al., 2006; Martin et al., 2019; Patel et al., 2013). For instance, numerous scholars (Chen \& Kannan-Narasimhan, 2015; Gassmann et al., 2012; Gatignon \& Xuereb,1997; Gupta et al.,2006; Raisch \& Tushman, 2016) argued that large firms having greater resource availability, are able to proceed for structural ambidexterity by creating subsets of their operations and staff, giving them due support to carry out either exploration or exploitation in more clearly defined boundaries within their respective units. Lubatkin et al., (2006) also supported this notion of structural separation appropriateness for larger organizations in perusing the OA. Adding to this Hill \& Birkinshaw, (2014) argued that larger organizations have sufficient resources and the option to invest on exploratory activities, while the smaller firms due to resource scarcity are incapable to maintain separate exploration in the long run (Burgers \& Covin, 2016; Fourné et al., 2019). Further, Martin et al., (2019) and Patel et al., (2013) are in a view that since small firms, having a smaller workforce and usually a flatter hierarchy, developing human capability is more critical for such organizations thus investments in behavioral capacity of human resource is more appropriate rather than focusing on creating separate units. Therefore, literature has advocated that contextual ambidexterity and alternative structural approaches small and resource-constrained organizations (Cao, Gedajlovic \& Zhang et al., 2009; Chang \& Hughes, 
2012; Lubatkin et al. 2006; Raisch, Birkinshaw, Probst \& Tushman, 2009; Voss \& Voss, 2013) as these organizations lack resources and scale economies to make specialization in both exploration and exploitation (Csaszar, 2013 \& 2014; Pertusa-Ortega, \& Molina-Azorín, 2018).

\section{TOWARDS A CONDUCIVE INTEGRATED APPROACH}

As organizational structure plays a key role in implementation of chalked out organizational strategies and facilities the needed due course of actions towards ultimate objective, do as needed for implementation of ambidexterity (Asif, 2017; Csaszar, 2013; Fourné et al., 2019; Hansen et al., 2018; Martin et al., 2019). Therefore, organizational management needs to design a conducive structural design for maneuvering exploration and exploitation for attaining OA. Previous studies (Benner \& Tushman, 2003; Tushman \& O’Reilly, 1996) have by and large focused on structural differentiation through integration mechanisms aimed to increase knowledge flows across organizational units engaged in exploitation and exploration (Jansen et al., 2009). Although structural differentiation has its own importance in tackling conflicting demands of exploration and exploitation activities, from the contextual approach of ambidexterity, other organizational structural designs can also serve the purpose attaining OA (Adler \& Heckscher, 2013; Chang \& Hughes, 2012; Chang, Hughes \& Hotho,2011; Jansen et al., 2009; Lyytinen et al., 2010; Pertusa-Ortega, \& Molina-Azorín, 2018).

Below are few alternative structural designs that are possible options that resourceorganizations can adopt to attain OA in turn organizational prosperity. Which is apparently, as suggested in the literature, is possible in two ways. First, by combined structural characteristics approach i.e. combination of both mechanistic and organic structural characteristics; and second, single structural character approach by predominately focusing on single organic structural arrangement.

\section{Centralization and Connectedness}

Centralization refers to the hierarchical decision making authority where ultimate power and decision-making and responsibility for coordination is vertically concentrated at the top of the organizational chart (Chen \& Huang, 2007; Ferrell \& Skinner, 1988; Hollenbeck, 2000; Jansen, Van den Bosch, \& Volberda, 2006; Menon \& Varadarajan, 1992; Tran \& Tian, 2013).

Centralization tends to prevent due to flexibility required for strategic solutions to problems since centralized decision making often translates into processes that prove counterproductive for the solution-oriented creative environment (Cao, Simsek \& Zhang, 2010; Deal \& Kennedy, 1982; Kouropalatis, Hughes, \& Morgan, 2012). In view of the fact that centralized structural arrangements diminish the quality of information decision-makers receive, due to limited cognitive capacities and higher communication costs in terms of the effort for obtaining approval from top-level management (Cao et al., 2010). Further, though centralization the quality of the information received could be compromised because specialization of work at each hierarchical level leads to sensory and perceptual differences that could cause distortion in communicated information (Sheremata, 2000). Since the decision making remains right on top, therefore predictably innovative and diverse ideas are ruled out from the decision-making process, leading to ill-favored new knowledge and innovation outcomes (Jansen et al., 2006; Pertusa-Ortega, \& Molina-Azorín, 2018; Yang, Zhou \& Zhang, 2015). In other words, it is restrictive to explorative requirements.

However, centralization is considered advantageous in responding to exploitative requirements. As previous research has suggested that centralization is necessary for exploitation and commercialization (Duncan, 1976; Siggelkow \& Levinthal, 2003). It has been also argued that centralization promotes consensus-making and unified deployment (Wally \& 
Baum, 1994), which are exploitation-natured activities. It is so that in decentralized structural arrangements, the management usually transmit specifically required information timely so as by utilizing its current capabilities the organization may respond swiftly to market uncertainties (Chang et al., 2011; Jansen et al., 2006; Perrow, 1984; Popadiuk \& Bido, 2016; Sheremata, 2000).

To counter the disadvantage associated with centralized arrangement pertaining to explorative activities, the literature suggests that taking into consideration additional organic structural characteristic i.e. connectedness may help to resolve exploration issues. As connectedness describes how human resources may collaborate through direct engagement and contact within the organization (Atuahene-Gima, 2003; Jansen, Van Den Bosch \& Volberda., 2005; Sheremata, 2000). Connectedness helps organizations to promote openness to knowledge resources by strengthening the links among human resources engaged in different functions (Clark \& Fujimoto, 1991; Jaworski \& Kohli, 1993). This, in turn, can facilitate exploration by facilitating the combination and development of individual knowledge and ideas that support such innovations (Atuahene-Gima, 2003; Jansen et al., 2005; McFadyen \& Cannella, 2004). In addition, highly dense networks, through diffusing strong norms, assist in the establishment of collective behavioral beliefs (Rowley, Behrens \& Krackhardt, 2000; Uzzi, 1997) which leads to rapid problem-solving (Atuahene-Gima, 2003). In addition, dense social relations enable members of the organization to share experiences concerning the implementation of certain enhancements. Also, connectedness though informally connected human resources can foster trust and cooperation (Adler \& Kwon, 2002; Popadiuk \& Bido, 2016), utilizing which the organization can foster explorative innovation (Atuahene-Gima, 2003; Chang et al., 2011; Jansen et al., 2005; Rowley et al., 2000).

Therefore, an organization can use centralization to ensure exploitation from the one end and from another end connectedness will reinforce organizational exploration activities. Together, these two structural arrangements will result in organizational ambidexterity.

\section{Formalization and Connectedness}

Mechanistic structural characteristics of formalization refer to the extent to which the rules, job description, procedures, instructions, responsibilities, and communications are formalized or written down (Deshpande \& Zaltman, 1982; Khandwalla, 1977; Pertusa-Ortega, ZaragozaSáez, \& Claver-Cortés, 2010; Wei, Yi, \& Yuan, 2011). In other words, formalization entails that procedures for organizational activities and organizational members' responsibilities should be specified and documented and organization and its members should follow such documented specific rules, procedures, and instructions accordingly. Formalization has been acknowledged that being an integration mechanism can facilitate and advance the integration of knowledge and its effective usage in the organization (Filippini, Güttel, Neirotti \& Nosella, 2012; Pertusa-Ortega et al., 2010; Wei et al., 2011). Katila and Ahuja (2002) argue that the exploitation of existing resources and activities triggers the need for exploration of new resources and activities, and such exploration resources and knowledge my further help in future exploitation activities. In this respect, formalization could facilitate this mechanism, as the new knowledge generated from exploration activities could further be arranged, documented and disseminated which could be productive for future exploitation intervention. Otherwise stated, formalization allows exploration and exploitation reiterate in cyclic form by utilizing exploitation of existing capabilities and routines, disseminating that knowledge throughout the organization, meanwhile, formalized arrangements facilitate the replication and diffusion of exploratory innovations through new knowledge. 
Predominantly there is a common understanding among scholars that formalization impedes the exploration process in the organization (Parker, 2014; Pertusa-Ortega, \& Molina-Azorín, 2018; Selcer \& Decker, 2012; Sinden, Hoy \& Sweetland, 2004; Wei et al., 2011). As coercive formalization by adopting strict formal rules and enforcing the compliance of such rules hampers deviance from current knowledge and restricts the new knowledge creation process which is a prerequisite of exploration efforts (Jansen et al., 2006; Lee \& Choi, 2003; Von Krogh, 1998). Likewise, in a way formalization encumbers the realization of incremental improvements (exploitation activities) in the organization, as such improvement could not be realized through blind adherence to the documented rigid rules. However, formalization tends to strengthen efficiency and the advancement of existing operations by establishing accustomed tendencies of behavior (Jansen et al. 2006; Kang \& Snell, 2009). In such organizational environment learning process focus on refinement of current knowledge (Chang \& Hughes, 2012; Kang \& Snell, 2009), which contemplative of exploitation process (March, 1991) and conducive exploitation process (Benner \& Tushman, 2003; He \& Wong, 2004; Levinthal \& March, 1993; Pertusa-Ortega, \& Molina-Azorín, 2018; Wei et al., 2011).

On the other hand, in contrast to mechanistic structure characterized by formalization, organic organizational structure tends to advocate simplifying routine by loosely connected rules and by providing room and flexibility to organizational members to experience their mode of operation and its execution (Chen, 2017; Kang \& Snell, 2009; Su, Yang \& Li, 2011). Connectedness is one feature of such an organic structure that encourages formal and informal knowledge sharing by disbursing individual and teams' knowledge from across the organization (Atuahene- Gima, 2005; Jansen et al., 2006; Jaworski \& Kohli, 1993). Further, it allows organizational members to combine tacit knowledge in such a fashion that may encourage explorative learning (March, 1991) which leads to the exploration process (He \& Wong, 2004; Ireland, Hitt, \& Sirmon, 2003). Networking organization members through flexible organizational structural characteristics could encourage informational communication and knowledge sharing could fuel and encourage exploration activities in an organization. Although some scholars (Jansen et al., 2006; Kang \& Snell, 2009) claimed that organizational connectedness better work for both exploration and exploitation simultaneously, and others have opposed this notion by saying that connectedness only supports exploration process (Chang et al., 2011; Popadiuk \& Bido, 2016).

However, this study argues that achieving exploration and exploitation simultaneously is hard to attain through connectedness in resource contained organizations where critical resources such as managerial skills and capabilities, internal technological resources are predominantly limited which are usually required to handle the situation in favor of organizational ambidexterity. Therefore, it seems more sound for resource-contained organizations to follow the parallel structure characterized by formalization and connectedness, for respectively addressing exploitation and exploration activities to attain organizational ambidexterity.

\section{Decentralization}

Decentralization has been considered as a dynamic participative philosophy of management in organization by referring it a selective delegation and distribution of power to all levels of the business hierarchy (Aiken \& Hage, 1968; Ferrell \& Skinner, 1988; Foss, Lyngsie, \& Zahra, 2015; Hollenbeck, 2000; Jaworski \& Kohli, 1993; Tran \& Tian, 2013).

In contrast to centralization, in decentralized organizational structural arrangements, decisionmaking is distributed at the different hierarchical levels which eventually leads to the innovative ideas generation and required change management (Olson, Slater \& Hult, 2005). Predominantly, during non-routine tasks and complex and changing business environment, 
decentralization could be more efficient by empowering managers for situational decision making and rapid implementation accordingly, for being close to the source of the problem (Jansen et al., 2006) as strategic decisions in dynamic environments are time-bounded and only applicable during limited timeframe (Feurer, Chaharbaghi \& Wargin, 1995). Thereby, decentralization opens up opportunities for continuous learning based on distributed ownership in decision making which can further be ensured by the organization that the highest quality knowledge is used in the process of decision making and implementation (Feurer et al., 1995; Kouropalatis et al, 2012).

Accordingly, by dispersing the powers through decentralization at different levels, as such provide an opportunity to managers to appropriately chase new opportunities based on environmental scanning and feedback, and effective use of existing knowledge can be carried out at each hierarchical levels in the organization (Foss et al.,2015). In other words, decentralization can promote exploitation activities. Relatedly, Exploration compels deviation from existing knowledge and exceptional problem solving, owing to ascertain customers' emerging demands, new products, services or technologies distant from existing ones (Jansen et al., 2005; Wei et al., 2011). Decentralization likely facilitates ad hoc problem solving that increases the range of alternatives to solutions and helps individuals to carry out exploratory activities (Chang \& Hughes, 2012; Jansen et al., 2005).

Additionally, decentralized structural arrangement may improve information flows (Feurer et al. 1995; Hempel, Zhang \& Han, 2012), and facilitate to concede the changes in customer demands, technological advancement and entrepreneurial opportunities which are crucial for carrying out exploration process (Jansen, Simsek \& Cao, 2012; Mihalache, Jansen, Van den Bosch \& Volberda, 2014; Wei et al., 2011). Putting together, Foss et al., (2015) argued that decentralization is needed for the adequate development of separate exploratory and exploitative activities because it provides autonomy to the different levels to make adjustments and modifications unilaterally. Furthermore, decentralization broadens the possibility that individuals seek innovative solutions (Damanpour, 1991 \& 1996; Jansen et al., 2006), are stimulated and committed to considering and using the information to pursue organizational ambidexterity (Cao et al., 2010). Therefore, decentralization per se can favor both exploitative and explorative activities (Pertusa-Ortega, \& Molina-Azorín, 2018).

\section{Enabling formalization}

Some scholars have argued that formalization might contribute in integrating exploratory and exploitative activities, but it is contingent on the level of formalization adopted by the organization (Chang, Hughes, 2012; Farjoun, 2010; Jansen et al., 2006; Pertusa-Ortega, \& Molina-Azorín, 2018; Wei et al., 2011).

Therefore, it has been argued that formalization to be viewed in line with the classification provided by Adler and Borys (1996) who classified organizational structural formalization into two categories i.e. coercive formalization and enabling formalization (Farjoun, 2010; Mom et al., 2009; Parker, 2014; Pertusa-Ortega, \& Molina-Azorín, 2018). Where coercive formalization specifies to rules and procedures of obligatory compliance without proving much flexibility and freedom (Johari \& Yahya, 2009; Parker, 2014; Sinden et al., 2004); enabling formalization, on the other hand, denotes to "rules and procedures that capture and codify best practice, designed with a wide range of contextual information to help employees interact creatively with the broader organization and environment" (Adler \& Borys, 1996). Some other scholars (Selcer \& Decker, 2012; Wei et al., 2011) classify it as high and low level of formalization, however, they differentiate between the two in terms of level of flexibility i.e. high 
formalization being more rigid and less formalization with more leeway (coercive formalization is discussed in section 4.2 above).

On contrary to coercive formalization, enabling formalization supposed to better respond to the prevailing environment in a conventional manner by facilitating the improvement of routines and practices that increase efficiency and ease the application of new knowledge. Thus, enabling formalization may emphasize exploitative innovation through the improvement of current products and processes. (Jansen et al. 2006; Pertusa-Ortega, \& Molina-Azorín, 2018; Wei et al., 2011). Further, enabling formalization can help organizational members to perform their tasks in an efficient manner to solve current work problems through flexible procedures and guides that enable them to confronted challenges and paradoxes (Sinden et al., 2004). In doing so, enabling formalization per se mobilizes human capital intelligence and experience by encouraging them to form mental models of the activities they are carrying out, and modify them as appropriate to fit for the accomplishment of tasks (Johari \& Yahya, 2009; Wouters \& Wilderom, 2008). Put it briefly, it can encourage the initiation of perfections in present tasks, which means, it can favor exploitative operational efforts.

In the same vein, it has been argued that apart from promoting exploitation activities, enabling formalization can also support explorative activities because it synchronizes some degree of flexibility and reinforces employees' participation and encouragement. It seems so that enabling formalization to give employees some room to comprehend so that their own tasks and responsibilities fit and align within the context (Wouters \& Wilderom, 2008), this, in turn, can stimulate individuals to engage in the creative process and perform exploration of new processes and activities. In a nutshell, enabling formalization upholds flexibility such as a way to learn from errors, transform problems into new opportunities, simplify problem-solving, and embolden innovativeness (Pertusa-Ortega, \& Molina-Azorín, 2018). Therefore, putting this two prospective together lead to the conclusion that enabling formalization promotes both exploration and exploitation activities, hence, could be helpful in attaining organizational ambidexterity.

\section{CONCLUSION}

This theoretical paper was aimed to explore alternative conducive structural approaches for attaining organizational ambidexterity in resource-constrained organizations. Our theoretical paper shield light on balancing both exploration and exploitation (i.e. balanced approach of organizational ambidexterity) is the most suitable pathway in attaining long term performance. Further, this study argued that the proposed structural separation approach is not feasible for resource-constrained organizations. Therefore, four alternative approaches towards organizational design; two chartered by a combination of mechanistic and organic organizational (e.g. centralization and connectedness; formalization and connectedness) and other two based on organic structure characteristics (e.g. decentralization and enabling formalization) are suggested that could help in attaining organizational ambidexterity. Therefore, based on these proposals, further empirical validations in resource-constrained organizations in different contexts and economies will be a valuable addition in enriching the theory and literature of organizational design and organizational ambidexterity.

\section{References}

Adler, P. S., \& Borys, B. (1996). Two types of bureaucracy: Enabling and coercive. Administrative science quarterly, 61-89.

Adler, P. S., \& Kwon, S. W. (2002). Social capital: Prospects for a new concept. Academy of management review, 27(1), 17-40. 
Adler, P., \& Heckscher, C. (2013). The collaborative, ambidextrous enterprise. Universia Business Review, (40), 3451.

Agostini, L., Nosella, A., \& Filippini, R. (2016). Towards an integrated view of the ambidextrous organization: A second-order factor model. Creativity and Innovation Management, 25(1), 129-141.

Aiken, M., \& Hage, J. (1968). Organizational interdependence and intra-organizational structure. American sociological review, 912-930.

Asif, M. (2017). Exploring the antecedents of ambidexterity: a taxonomic approach. Management Decision, 55(7), 1489-1505.

Atuahene-Gima, K. (2003). The effects of centrifugal and centripetal forces on product development speed and quality: how does problem solving matter?. Academy of management journal, 46(3), 359-373.

Atuahene-Gima, K. (2005). Resolving the capability-rigidity paradox in new product innovation. Journal of marketing, 69(4), 61-83.

Benner, M. J., \& Tushman, M. L. (2003). Exploitation, exploration, and process management: The productivity dilemma revisited. Academy of management review, 28(2), 238-256.

Boumgarden, P., Nickerson, J., \& Zenger, T. R. (2012). Sailing into the wind: Exploring the relationships among ambidexterity, vacillation, and organizational performance. Strategic Management Journal, 33(6), 587-610.

Burgers, J. H., \& Covin, J. G. (2016). The contingent effects of differentiation and integration on corporate entrepreneurship. Strategic Management Journal, 37(3), 521-540.

Burgers, J. H., Van Den Bosch, F. A., \& Volberda, H. W. (2008). Why new business development projects fail: Coping with the differences of technological versus market knowledge. Long range planning, 41(1), 55-73.

Burns, T., \& Stalker, G. M. (1961). The management of innovation. London: Tavistock.

Cao, Q., Gedajlovic, E., \& Zhang, H. (2009). Unpacking organizational ambidexterity: Dimensions, contingencies, and synergistic effects. Organization Science, 20(4), 781-796.

Cao, Q., Simsek, Z., \& Zhang, H. (2010). Modelling the joint impact of the CEO and the TMT on organizational ambidexterity. Journal of Management Studies, 47(7), 1272-1296.

Chandrasekaran, A., Linderman, K., \& Schroeder, R. (2012). Antecedents to ambidexterity competency in high technology organizations. Journal of Operations Management, 30(1-2), 134-151. doi:10.1016/j.jom.2011.10.002

Chang, Y. Y., \& Hughes, M. (2012). Drivers of innovation ambidexterity in small-to medium-sized firms. European Management Journal, 30(1), 1-17.

Chang, Y. Y., Hughes, M., \& Hotho, S. (2011). Internal and external antecedents of SMEs' innovation ambidexterity outcomes. Management Decision, 49(10), 1658-1676.

Chen, C. J., \& Huang, J. W. (2007). How organizational climate and structure affect knowledge management-The social interaction perspective. International journal of information management, 27(2), 104-118.

Chen, R. R., \& Kannan-Narasimhan, R. P. (2015). Formal integration archetypes in ambidextrous organizations. R\&D Management, 45(3), 267-286.

Chen, Y. (2017). Dynamic ambidexterity: How innovators manage exploration and exploitation. Business Horizons, 60(3), 385-394. doi:10.1016/j.bushor.2017.01.001

Clark, K. B., \& Fujimoto, T. (1991). Product development performance: Strategy, organization, and management in the world auto industry.

Csaszar, F. A. (2013). An efficient frontier in organization design: Organizational structure as a determinant of exploration and exploitation. Organization Science, 24(4), 1083-1101.

Csaszar, F. A. (2014). Bridging the gulf between executive characteristics and organizational outcomes: The intertwined roles of cognition, aggregation structure, and the environment. Aggregation Structure, and the Environment (August 31, 2014).

Damanpour, F. (1991). Organizational innovation: A meta-analysis of effects of determinants and moderators. Academy of management journal, 34(3), 555-590.

Damanpour, F. (1996). Organizational complexity and innovation: developing and testing multiple contingency models. Management science, 42(5), 693-716. 
Deal, T. E., \& Kennedy, A. A. (1982). Corporate cultures (pp. 110-134). Reading, MA: Addison Wesley.

Deshpande, R., \& Zaltman, G. (1982). Factors affecting the use of market research information: A path analysis. Journal of marketing research, 19(1), 14-31.

Duncan, R. (1976). The ambidextrous organization: Designing dual structures for innovation. R. Kilman, L. Pondy, D. Slevin, eds. The Management of Organizational Design, vol. 1.

Dutta, S. K., \& Guha, M. (2015). Coexistence of structural and contextual ambidexterity-evidences in Indian organisations. International Journal of Applied Management Science, 7(3), 177-193.

Farjoun, M. (2010). Beyond Dualism: Stability and Change As a Duality. Academy of Management Review, 35(2), 202-225.

Ferrell, O. C., \& Skinner, S. J. (1988). Ethical behavior and bureaucratic structure in marketing research organizations. Journal of marketing research, 25(1), 103-109.

Feurer, R., Chaharbaghi, K., \& Wargin, J. (1995). Analysis of strategy formulation and implementation at HewlettPackard. Management Decision, 33(10), 4-16.

Filippini, R., Güttel, W. H., Neirotti, P., \& Nosella, A. (2012). The different modes for absorbing knowledge: an analytic lens on absorptive capacity from a process perspective. International Journal of Knowledge Management Studies, 5(1-2), 45-65.

Ford, J. D., \& Ford, L. W. (1994). Logics of identity, contradiction, and attraction in change. Academy of Management Review, 19(4), 756-785.

Foss, N. J., Lyngsie, J., \& Zahra, S. A. (2015). Organizational design correlates of entrepreneurship: The roles of decentralization and formalization for opportunity discovery and realization. Strategic Organization, 13(1), 32-60.

Fourné, S. P., Rosenbusch, N., Heyden, M. L., \& Jansen, J. J. (2019). Structural and contextual approaches to ambidexterity: A meta-analysis of organizational and environmental contingencies. European Management Journal.

Gassmann, O., Widenmayer, B., \& Zeschky, M. (2012). Implementing radical innovation in the business: the role of transition modes in large firms. R\&D Management, 42(2), 120-132.

Gatignon, H., \& Xuereb, J. M. (1997). Strategic orientation of the firm and new product performance. Journal of marketing research, 34(1), 77-90.

Gibson, C. B., \& Birkinshaw, J. (2004). The antecedents, consequences, and mediating role of organizational ambidexterity. Academy of management Journal, 47(2), 209-226.

Gilbert, C. G. (2006). Change in the presence of residual fit: Can competing frames coexist?. Organization Science, 17(1), 150-167.

Gupta, A. K., Smith, K. G., \& Shalley, C. E. (2006). The interplay between exploration and exploitation. Academy of management journal, 49(4), 693-706.

Hansen, E. G., Wicki, S., \& Schaltegger, S. (2018). Structural ambidexterity, transition processes, and integration trade-offs: a longitudinal study of failed exploration. R\&D Management.

He, Z. L., \& Wong, P. K. (2004). Exploration vs. exploitation: An empirical test of the ambidexterity hypothesis. Organization science, 15(4), 481-494.

Hempel, P. S., Zhang, Z. X., \& Han, Y. (2012). Team empowerment and the organizational context: Decentralization and the contrasting effects of formalization. Journal of management, 38(2), 475-501.

Heracleous, L., Papachroni, A., Andriopoulos, C., \& Gotsi, M. (2017). Structural ambidexterity and competency traps: Insights from Xerox PARC. Technological Forecasting and Social Change, 117, 327-338.

Hill, S. A., \& Birkinshaw, J. (2014). Ambidexterity and survival in corporate venture units. Journal of management, 40(7), 1899-1931.

Hollenbeck, J. (2000). A Structural Approach to External and Internal Person-Team Fit. Applied Psychology, 49(3), 534-549.

Ireland, R. D., Hitt, M. A., \& Sirmon, D. G. (2003). A model of strategic entrepreneurship: The construct and its dimensions. Journal of management, 29(6), 963-989.

Jansen, J. J., George, G., Van den Bosch, F. A., \& Volberda, H. W. (2008). Senior team attributes and organizational ambidexterity: The moderating role of transformational leadership. Journal of Management Studies, 45(5), 9821007. 
Jansen, J. J., Simsek, Z., \& Cao, Q. (2012). Ambidexterity and performance in multiunit contexts: Cross-level moderating effects of structural and resource attributes. Strategic Management Journal, 33(11), 1286-1303.

Jansen, J. J., Tempelaar, M. P., Van den Bosch, F. A., \& Volberda, H. W. (2009). Structural differentiation and ambidexterity: The mediating role of integration mechanisms. Organization science, 20(4), 797-811.

Jansen, J. J., Van Den Bosch, F. A., \& Volberda, H. W. (2005). Managing potential and realized absorptive capacity: how do organizational antecedents matter?. Academy of management journal, 48(6), 999-1015.

Jansen, J. J., Van Den Bosch, F. A., \& Volberda, H. W. (2006). Exploratory innovation, exploitative innovation, and performance: Effects of organizational antecedents and environmental moderators. Management science, 52(11), 1661-1674.

Jaworski, B. J., \& Kohli, A. K. (1993). Market orientation: antecedents and consequences. Journal of marketing, 57(3), 53-70.

Johari, J., \& Yahya, K. K. (2009). Linking organizational structure, job characteristics, and job performance construct: A proposed framework. International journal of business and management, 4(3), 145-152.

Junni, P., Sarala, R. M., Taras, V., \& Tarba, S. Y. (2013). Organizational ambidexterity and performance: A metaanalysis. Academy of Management Perspectives, 27(4), 299-312.

Junni, P., Sarala, R. M., Tarba, S. Y., Liu, Y., \& Cooper, C. L. (2015). Guest editors' introduction: The role of human resources and organizational factors in ambidexterity. Human Resource Management, 54(S1), s1-s28.

Kang, S. C., \& Snell, S. A. (2009). Intellectual capital architectures and ambidextrous learning: a framework for human resource management. Journal of Management Studies, 46(1), 65-92.

Katila, R., \& Ahuja, G. (2002). Something old, something new: A longitudinal study of search behavior and new product introduction. Academy of management journal, 45(6), 1183-1194.

Khandwalla, P. N. (1977). The design of organizations. New York: Harcourt, Brace and Jovanovich.

Kouropalatis, Y., Hughes, P., \& Morgan, R. E. (2012). Pursuing "flexible commitment" as strategic ambidexterity: An empirical justification in high technology firms. European Journal of Marketing, 46(10), 1389-1417.

Lavie, D., Kang, J., \& Rosenkopf, L. (2011). Balance within and across domains: The performance implications of exploration and exploitation in alliances. Organization Science, 22(6), 1517-1538.

Lavie, D., Stettner, U., \& Tushman, M. L. (2010). Exploration and exploitation within and across organizations. The Academy of Management Annals, 4(1), 109-155.

Lawrence, P. R., \& Lorsch, J. W. (1967). Differentiation and integration in complex organizations. Administrative science quarterly, 1-47.

Lee, H., \& Choi, B. (2003). Knowledge management enablers, processes, and organizational performance: An integrative view and empirical examination. Journal of management information systems, 20(1), 179-228.

Levinthal, D. A., \& March, J. G. (1993). The myopia of learning. Strategic management journal, 14(S2), 95-112.

Lewis, P. (2000). Realism, causality and the problem of social structure. Journal for the theory of Social Behaviour, 30(3), 249-268.

Lubatkin, M. H., Simsek, Z., Ling, Y., \& Veiga, J. F. (2006). Ambidexterity and performance in small-to medium-sized firms: The pivotal role of top management team behavioral integration. Journal of management, 32(5), 646-672.

Lyytinen, K., Rose, G., \& Yoo, Y. (2010). Learning routines and disruptive technological change: Hyper-learning in seven software development organizations during internet adoption. Information Technology \& People, 23(2), 165-192.

March, J. G. (1991). Exploration and exploitation in organizational learning. Organization science, 2(1), 71-87.

Martin, A., Keller, A., \& Fortwengel, J. (2019). Introducing conflict as the microfoundation of organizational ambidexterity. Strategic Organization, 17(1), 38-61.

McFadyen, M. A., \& Cannella Jr, A. A. (2004). Social capital and knowledge creation: Diminishing returns of the number and strength of exchange relationships. Academy of management Journal, 47(5), 735-746.

Menon, A., \& Varadarajan, P. R. (1992). A model of marketing knowledge use within firms. Journal of marketing, 56(4), 53-71. 
Mihalache, O. R., Jansen, J. J., Van den Bosch, F. A., \& Volberda, H. W. (2014). Top management team shared leadership and organizational ambidexterity: A moderated mediation framework. Strategic Entrepreneurship Journal, 8(2), 128-148.

Mom, T. J., Van Den Bosch, F. A., \& Volberda, H. W. (2009). Understanding variation in managers' ambidexterity: Investigating direct and interaction effects of formal structural and personal coordination mechanisms. Organization Science, 20(4), 812-828.

Nemanich, L. A., \& Vera, D. (2009). Transformational leadership and ambidexterity in the context of an acquisition. The Leadership Quarterly, 20(1), 19-33.

O’Reilly III, C. A., \& Tushman, M. L. (2008). Ambidexterity as a dynamic capability: Resolving the innovator's dilemma. Research in organizational behavior, 28, 185-206.

Olson, E. M., Slater, S. F., \& Hult, G. T. M. (2005). The performance implications of fit among business strategy, marketing organization structure, and strategic behavior. Journal of marketing, 69(3), 49-65.

O'Reilly III, C. A., \& Tushman, M. L. (2011). Organizational ambidexterity in action: How managers explore and exploit. California management review, 53(4), 5-22.

O'Reilly III, C. A., \& Tushman, M. L. (2013). Organizational ambidexterity: Past, present, and future. Academy of management Perspectives, 27(4), 324-338.

Parker, S. K. (2014). Beyond Motivation: Job and Work Design for Development, Health, Ambidexterity, and More. Annual Review of Psychology, 65(1), 661-691.

Patel, P. C., Messersmith, J. G., \& Lepak, D. P. (2013). Walking the tightrope: An assessment of the relationship between high-performance work systems and organizational ambidexterity. Academy of Management Journal, 56(5), 1420-1442.

Perrow, C., \& Accidents, N. (1984). Living with high-risk technologies. New York: Ba-sic. PerrowNormal Accidents: Living With High-Risk Technologies1984.

Pertusa-Ortega, E. M., \& Molina-Azorín, J. F. (2018). A joint analysis of determinants and performance consequences of ambidexterity. BRQ Business Research Quarterly, 21(2), 84-98.

Pertusa-Ortega, E. M., Zaragoza-Sáez, P., \& Claver-Cortés, E. (2010). Can formalization, complexity, and centralization influence knowledge performance?. Journal of Business Research, 63(3), 310-320.

Popadiuk, S., \& Bido, D. D. S. (2016). Exploration, exploitation, and organizational coordination mechanisms. Revista de Administração Contemporânea, 20(2), 238-260.

Raisch, S., \& Birkinshaw, J. (2008). Organizational ambidexterity: Antecedents, outcomes, and moderators. Journal of management, 34(3), 375-409.

Raisch, S., \& Tushman, M. L. (2016). Growing new corporate businesses: From initiation to graduation. Organization Science, 27(5), 1237-1257.

Raisch, S., Birkinshaw, J., Probst, G., \& Tushman, M. L. (2009). Organizational ambidexterity: Balancing exploitation and exploration for sustained performance. Organization science, 20(4), 685-695.

Rowley, T., Behrens, D., \& Krackhardt, D. (2000). Redundant governance structures: An analysis of structural and relational embeddedness in the steel and semiconductor industries. Strategic management journal, 21(3), 369386.

Selcer, A., \& Decker, P. (2012). The structuration of ambidexterity: An urge for caution in organizational design. International Journal of Organizational Innovation, 5(1).

Sheremata, W. A. (2000). Centrifugal and centripetal forces in radical new product development under time pressure. Academy of management review, 25(2), 389-408.

Siggelkow, N., \& Levinthal, D. A. (2003). Temporarily divide to conquer: Centralized, decentralized, and reintegrated organizational approaches to exploration and adaptation. Organization Science, 14(6), 650-669.

Simsek, Z. (2009). Organizational ambidexterity: Towards a multilevel understanding. Journal of management studies, 46(4), 597-624.

Sinden, J. E., Hoy, W. K., \& Sweetland, S. R. (2004). An analysis of enabling school structure: Theoretical, empirical, and research considerations. Journal of Educational Administration, 42(4), 462-478.

Smith, W. K., \& Tushman, M. L. (2005). Managing strategic contradictions: A top management model for managing innovation streams. Organization science, 16(5), 522-536. 
Su, Z., Li, J., Yang, Z., \& Li, Y. (2011). Exploratory learning and exploitative learning in different organizational structures. Asia Pacific Journal of Management, 28(4), 697-714.

Thompson, J. D. 1967. Organizations in action. New York: McGraw-Hill.

Tran, Q., \& Tian, Y. (2013). Organizational structure: Influencing factors and impact on a firm. American Journal of Industrial and Business Management, 3(2), 229.

Tushman, M. L., \& O'Reilly III, C. A. (1996). Ambidextrous organizations: Managing evolutionary and revolutionary change. California management review, 38(4), 8-29.

Uzzi, B. (1997). Social structure and competition in interfirm networks: The paradox of embeddedness. Administrative science quarterly, 35-67.

Von Krogh, G. (1998). Care in knowledge creation. California management review, 40(3), 133-153.

Voss, G. B., \& Voss, Z. G. (2013). Strategic ambidexterity in small and medium-sized enterprises: Implementing exploration and exploitation in product and market domains. Organization Science, 24(5), 1459-1477.

Wally, S., \& Baum, J. R. (1994). Personal and structural determinants of the pace of strategic decision making. Academy of Management journal, 37(4), 932-956.

Wei, Z., Yi, Y., \& Yuan, C. (2011). Bottom-up learning, organizational formalization, and ambidextrous innovation. Journal of Organizational Change Management, 24(3), 314-329.

Wouters, M., \& Wilderom, C. (2008). Developing performance-measurement systems as enabling formalization: A longitudinal field study of a logistics department. Accounting, Organizations and Society, 33(4-5), 488-516.

Yang, Z., Zhou, X., \& Zhang, P. (2015). Discipline versus passion: Collectivism, centralization, and ambidextrous innovation. Asia Pacific Journal of Management, 32(3), 745-769. 